\title{
ANALYTICAL METHOD DEVELOPMENT AND VALIDATION OF DABIGATRAN ETEXILATE RELATED SUBSTANCE IN PHARMACEUTICAL DOSAGE FORM BY REVERSE-PHASE - HIGH-PERFORMANCE LIQUID CHROMATOGRAPHY
}

\author{
RAJESH NAWALE ${ }^{1 *}$, SHANKAR POL ${ }^{2}$, PRASHANT PURANIK ${ }^{3}$, ANWAR DAUD ${ }^{4}$, VISHAL RAJKONDAWAR ${ }^{4}$ \\ ${ }^{1}$ Department of Pharmacology, Faculty of Pharmacy, Government College of Pharmacy, Dr. BAMU, Aurangabad - 431 005, Maharashtra, \\ India. ${ }^{2}$ Department of Pharmacy, Research Scholar, YB Chavan College of Pharmacy, Dr. BAMU, Aurangabad - 431 001, Maharashtra, India. \\ ${ }^{3}$ Department of Pharmaceutics, Faculty of Pharmacy, University Department of Pharmaceutical Sciences, RTMNU, Nagpur - 440 033, \\ Maharashtra, India. ${ }^{4}$ Research and Development Centre, ZIM Laboratories Limited, Kalmeshwar, Nagpur - 441 501, Maharashtra, India. \\ Email: nawale_pharmacy@yahoo.com
}

Received: 02 May 2018, Revised and Accepted: 22 June 2018

ABSTRACTS

Objective: The objective of the study was to develop and validate new, simple, and selective reverse-phase-high-performance liquid chromatography (RP-HPLC) method for the quantitative determination of Dabigatran Etexilate (DE) and its impurities in pharmaceutical dosage form as per the International Conference on Harmonization guidelines.

Method: Chromatographic analysis was performed on Princeton SPHER-100 C18 (250 × $4.6 \mathrm{~mm}, 5 \mu \mathrm{m}) \mathrm{HPLC}$ column, maintained at $50^{\circ} \mathrm{C}$ column temperatures, $6^{\circ} \mathrm{C}$ sample tray temperature, and detection monitored at $225 \mathrm{~nm}$. The mobile phase consisted of acetonitrile:phosphate buffer ( $\mathrm{pH} 2.5$ ) $(33: 67 \mathrm{~V} / \mathrm{V})$. The flow rate was maintained at $1.0 \mathrm{ml} / \mathrm{min}$.

Results: The system suitability results indicate good performance of the system. Specificity study indicates that there is no interference of placebo and blank. The percentage relative standard deviation (RSD) of six preparations for known and unknown impurity in the sample solution is found below 10\%; hence, the method is precise. The calibration curve for DE (unknown impurity), Impurity A was linear from 0.38 to $4.5 \mu \mathrm{g} / \mathrm{ml}$ (correlation coefficients [r2] for unknown Impurity [DE] and Impurity A are 0.996 and 0.999, respectively). The calibration curve for Impurity B and Impurity E was linear from 0.38 to $9.00 \mu \mathrm{g} / \mathrm{ml}$ (r2 for Impurity B and Impurity E are 0.999 and 0.999 , respectively); hence, the method is linear. Accuracy for DE (unknown Impurity), Impurity A, Impurity B, and Impurity E are found within 80\%-120\%; hence, the method is accurate. The percentage RSD for a standard solution is found below $5 \%$ up to $24 \mathrm{~h}$, and percentage impurity change in the sample solution is found below $0.1 \%$ up to $18 \mathrm{~h}$; hence, standard solution is stable up to $24 \mathrm{~h}$, and sample solution is stable up to $18 \mathrm{~h}$.

Conclusion: The developed method is new, simple, adequate, specific, precise, linear, and accurate for the determination of DE and its impurities in pharmaceutical dosage forms.

Keywords: Dabigatran etexilate, International Conference on Harmonization Guidelines, Reverse-phase-high-performance liquid chromatography, Method development, Method validations.

(C) 2018 The Authors. Published by Innovare Academic Sciences Pvt Ltd. This is an open access article under the CC BY license (http://creativecommons. org/licenses/by/4. 0/) DOI: http://dx.doi.org/10.22159/ajpcr.2018.v11i10.27043

\section{INTRODUCTION}

Dabigatran Etexilate (DE) (BIBR 1048) is a newly approved oral direct thrombin inhibitor which is indicated for anticoagulation therapy to reduce the risk of strokes and systemic embolism in patients with non-valvular atrial fibrillation. DE is marketed as "PRADAXA" in the form of DE Mesylate (DEM) (BIBR $1048 \mathrm{MS}$ ) salt as $75 \mathrm{mg}, 110 \mathrm{mg}$, and $150 \mathrm{mg}$ immediate release capsule. DE is ester prodrug, after oral administration, DE is rapidly absorbed and completely hydrolyzed to its active moiety, Dabigatran (BIBR 953), by non-specific abundant esterases in the gut, plasma, and liver. It is being studied for various clinical indications and in some cases it offers an alternative and beneficial as compare to warfarin as the preferred orally administered anticoagulant ("blood thinner") because it does not require frequent monitoring of the clotting tendency of blood while offering similar results in terms of efficacy [1-4].

Chemically, DEM is a mesylate salt of a prodrug DE of which Dabigatran is an active therapeutic ingredient. DEM contains two ester functional groups (ethyl ester and etexilate ester). The di-ester is essentially a prodrug for the corresponding zwitterion, and the nomenclature and strength are based on the relevant di-ester, intrinsic neutral form [5].
The chemical name for DEM, a direct thrombin inhibitor, is $\beta$-Alanine, $\mathrm{N}-[[2-[[[4-[[[$ (hexyloxy) carbonyl] amino] iminomethyl] phenyl] amino $]$ methyl] -1-methyl-1H-benzimidazol-5-yl] carbonyl]-N-2-pyridinyl-ethyl ester, methanesulfonate. The empirical formula is $\mathrm{C} 34 \mathrm{H} 41 \mathrm{~N} 705 \cdot \mathrm{CH} 4 \mathrm{O} 3 \mathrm{~S}$ and the molecular weight is 723.86 (mesylate salt), 627.75 (DE - free base) and 471.51 (Dabigatran - active moiety), respectively. The structural formulae of DEM, DE, and Dabigatran are presented in Figs. 1-3.

There are several processes and degradation impurities of DE, which are originated through the synthesis process and degradation during storage stability. Even several process impurities and degradation impurities of DE reported in prior literature; there are only three main degradation impurities of DE. The structure and details of the three main impurities A, B, and E are represented in Table 1.

As per literature survey, different assay methods such as UV and HPLC were developed for estimation of Dabigatran from finished dosage form and bulk API [6,7]. There is no HPLC method specified for determination of DE and its related substances in official pharmacopeias (USP and European Pharmacopoeia). However, few methods have been reported in literature for the determination of $\mathrm{DE}$, and its impurities in formulated products which are represented in Table 2 . 
Reverse phase liquid chromatography has been proven as a versatile, sensitive, reproducible, and highly precise method for its ability to separate the complex mixture of drug substances with impurities and its easy handling [13]. All these advantages of RP-HPLC make this the first choice of modern chemists. Hence, in this scenario, a reproducible

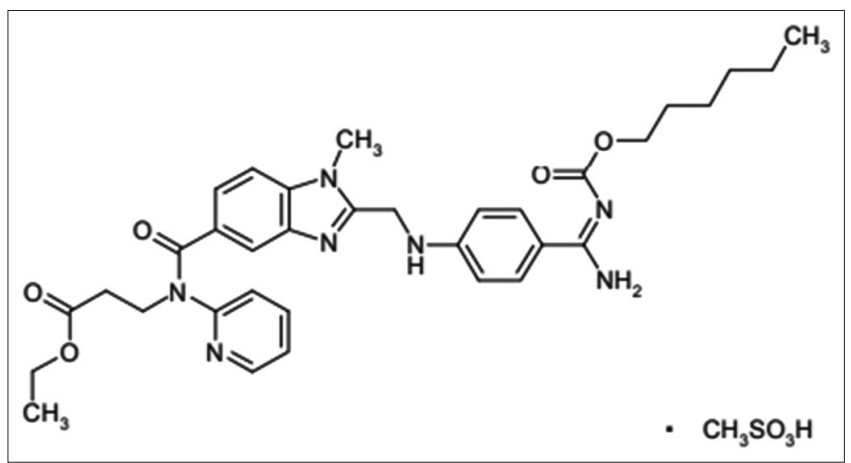

Fig. 1: Dabigatran etexilate mesylate (salt)

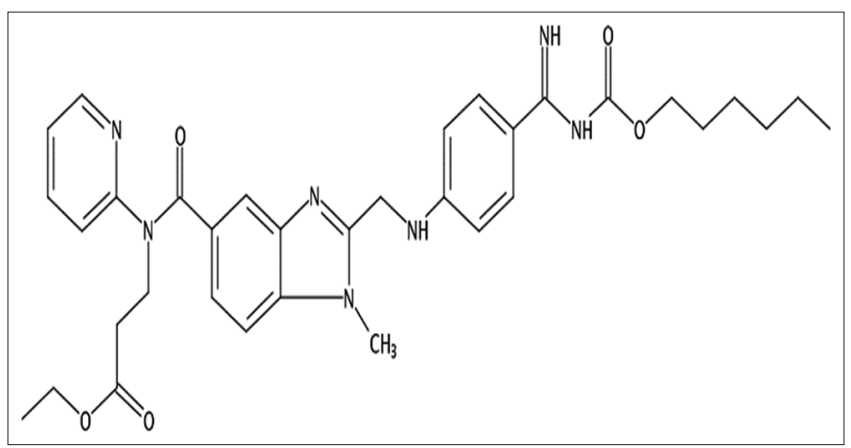

Fig. 2: Dabigatran etexilate (prodrug)<smiles>Cn1c(CNc2ccc(C(=N)N)cc2)nc2cc(C(=O)N(CCC(=O)O)c3ccccn3)ccc21</smiles>

Fig. 3: Dabigatran (active drug) and accurate method of analysis with properly documented validation gives huge support to the pharmaceutical industry. Hence, there is a need to develop newer stability indicating method by HPLC to make it simple and economical. All the above methods are gradient type RPHPLC methods. Hence, it is needed to develop novel, simple, isocratic, economic HPLC method for separation of DE and impurities. Hence, we proceeded with HPLC method development and validation as per International Conference on Harmonization (ICH) guidelines. The present analytical work comprises simple, precise, rapid, sensitive, and accurate method for the estimation of DE and its known main impurities A, B, and E. Therefore, the present work is aimed to develop a new and economic method for determination of DE in the pharmaceutical formulation in the presence of degradation product. Chromatographic

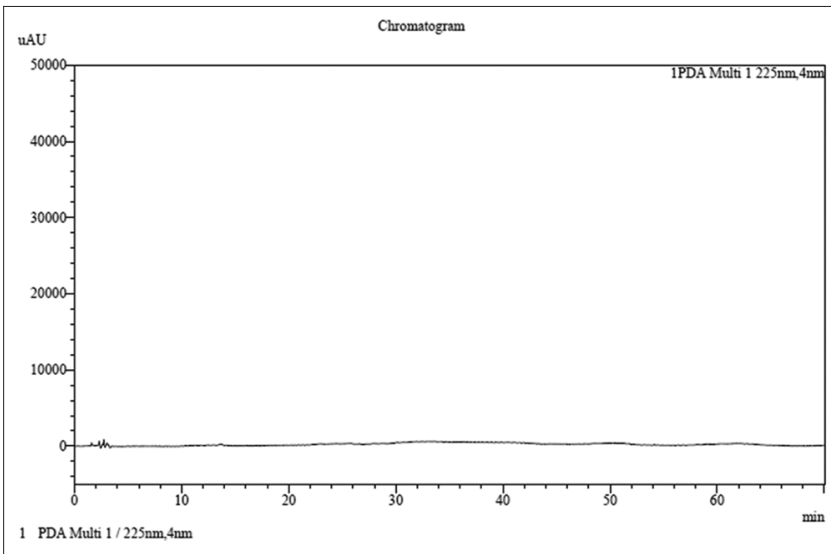

Fig. 4: Chromatogram of blank

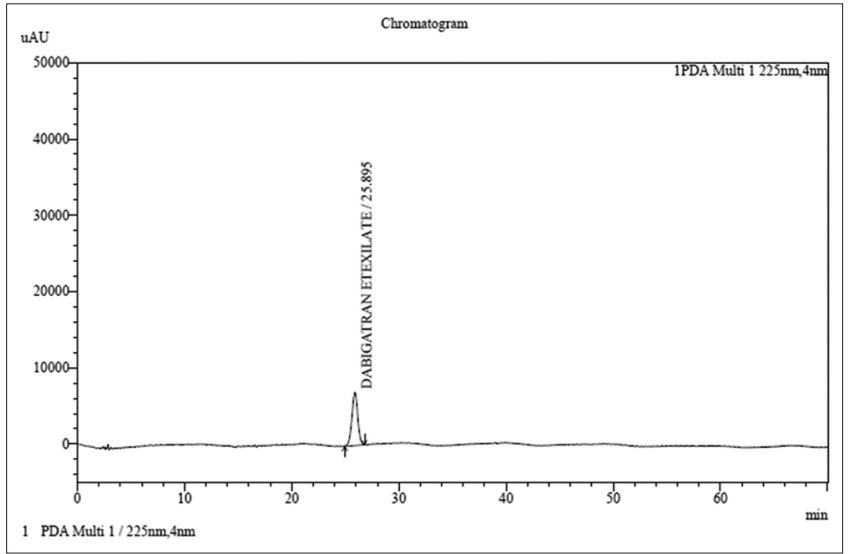

Fig. 5: Chromatogram of Dabigatran etexilate standard

Table 1: The structure and details of three known impurities A, B, and E

Name of the impurity
$\begin{aligned} & \text { Impurity A: Ethyl-3-(2-(c(4-Carbamimidoyl phenyl) amino) } \\ & \text { methyl)-l-methyl-N-(pyridin-2-yl)-1H-benzo (d) imidazole-5-carboxamido) } \\ & \text { propanoate }\end{aligned}$
$\begin{aligned} & \text { Impurity B: 3-(2- }\left(\left(\left(4-\left(\mathrm{N}^{\prime}-((\text { hexyloxy) carbonyl) carbamimidoyl) }\right.\right.\right.\right. \\ & \text { phenyl) amino) methyl)-1-methyl- } \mathrm{N}-(\text { pyridin-2-yl) -1 H-benzo[ d] } \\ & \text { imidazole-5-carboxamido) propanoic acid. }\end{aligned}$
$\begin{aligned} & \text { Impurity E: Ethyl 3-(2-(c(4--((hexyloxy) carbonyl) carbamoyl) phenyl) amino) } \\ & \text { methyl)-1-methyl N-(pyridin-2-yl) -1 H -benzo [d] imidazole-5-carboxamido) } \\ & \text { propanoate }\end{aligned}$


conditions that give the best resolution with minimal elution time for the DE and its degradation product. This makes the method to be applied in routine work and quantitative determination of the drug and its degradation product. Moreover, it is more sensitive, accurate, and precise method.

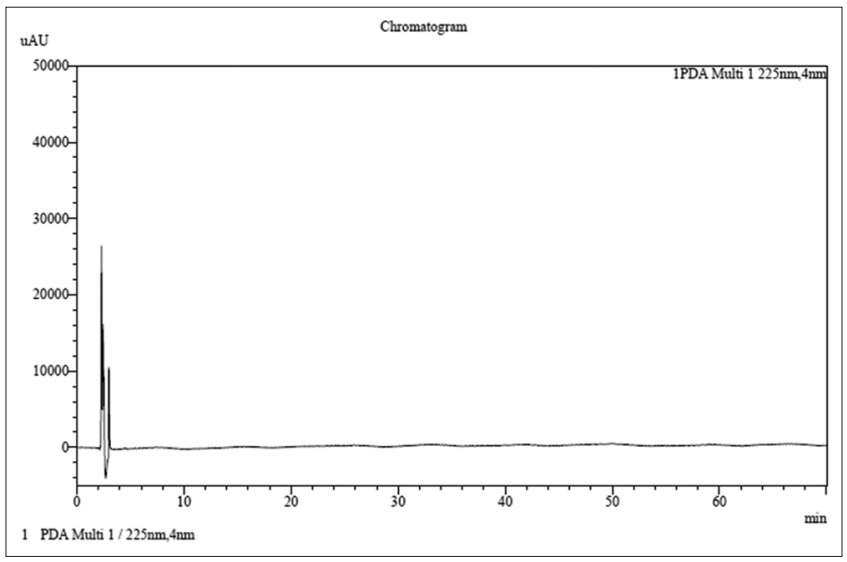

Fig. 6: Chromatogram of placebo

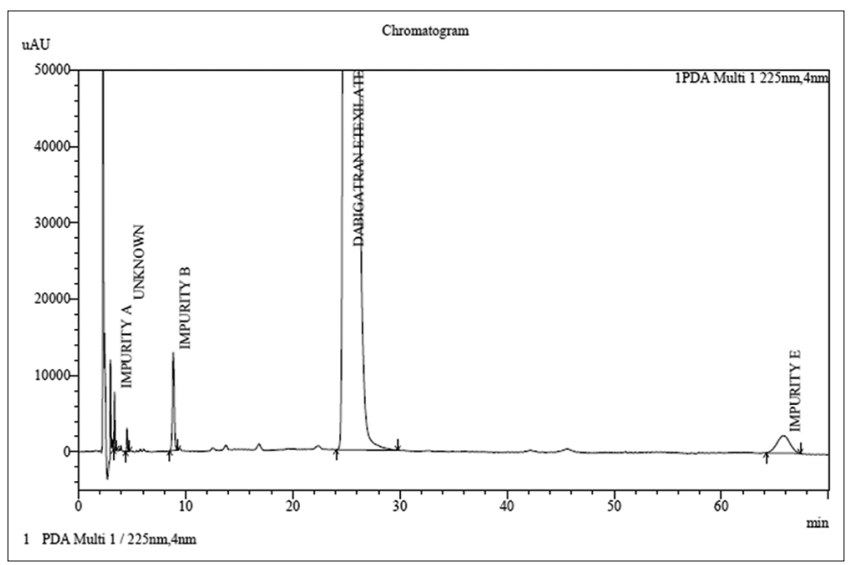

Fig. 7: Chromatogram of Dabigatran Etexilate sample

\section{METHODS}

Chemicals and solvents

DEM (drug) and impurities A, B, and E were provided by ZIM Laboratories Limited. All the chemicals and reagents were used in HPLC grade. Potassium dihydrogen phosphate (AR grade) was used for preparing buffer solution and adjusting the $\mathrm{pH}$ to 2.5 with $10 \%$

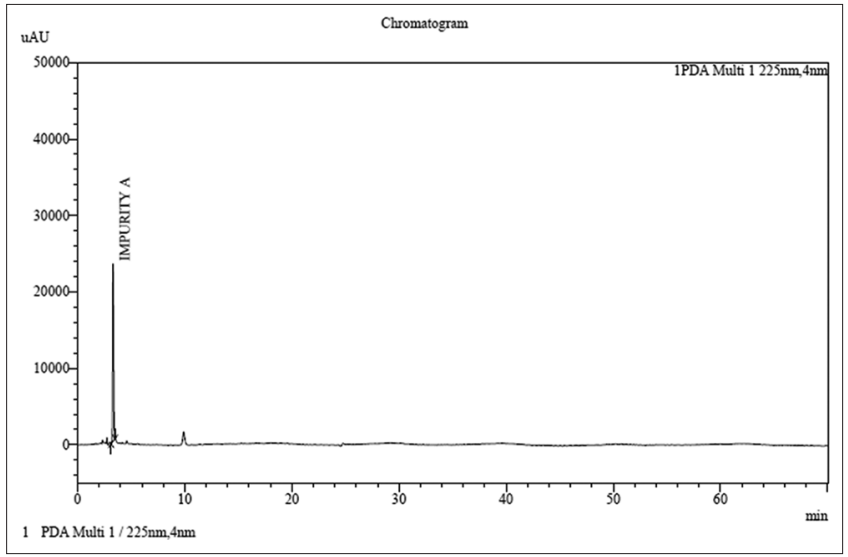

Fig. 8: Chromatogram of Impurity A

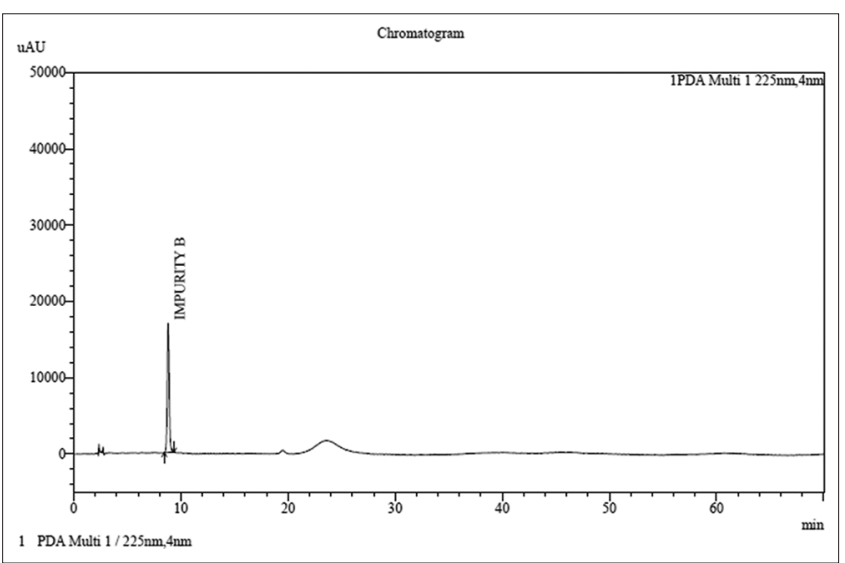

Fig. 9: Chromatogram of Impurity B

Table 2: Literature review on HPLC methods for determination of DE and its impurities [8-12]

\begin{tabular}{|c|c|c|c|c|c|c|}
\hline Author and $y$ & $\begin{array}{l}\text { Eluent } \\
\text { mode }\end{array}$ & Column & Mobile phase & $\begin{array}{l}\text { Column } \\
\text { temperature }\left({ }^{\circ} \mathrm{C}\right)\end{array}$ & RT (Min) & Wavelength \\
\hline Sandeep et al. & Gradient & $\begin{array}{l}\text { YMC Pack ODS A, } \\
150 * 4.6 \mathrm{~mm}, 5 \mathrm{mcg}\end{array}$ & $\begin{array}{l}\text { Mobile phase A: Buffer (potassium } \\
\text { di hydrogen phosphate) }(\mathrm{pH} 4.5) \\
\text { mobile phase B: Acetonitrile }\end{array}$ & -- & 21.2 & $220 \mathrm{~nm}$ \\
\hline Dare et al. & Gradient & $\begin{array}{l}\text { Poroshell } 120 \text { EC - } 18 \\
(150 \mathrm{~mm} \times 4.6 \mathrm{~mm}, 2.7 \mu)\end{array}$ & $\begin{array}{l}\text { Methanol: Buffer (hexane-1 } \\
\text { sulfonic acid sodium salt } \\
\text { monohydrate (pH 6.5) }\end{array}$ & $30^{\circ} \mathrm{C}$ & 26.97 & $230 \mathrm{~nm}$ \\
\hline Sreenivas et al. & Gradient & $\begin{array}{l}\text { Inertsil ODS-4, } 5 \mathrm{~m} \\
(250 \mathrm{~mm} \times 4.6 \mathrm{~mm})\end{array}$ & $\begin{array}{l}\text { Mobile phase } \\
\text { A: Phosphate (potassium } \\
\text { dihydrogen orthophosphate) } \\
\text { buffer (pH 3.0) mobile phase B: } \\
\text { Acetonitrile }\end{array}$ & $25^{\circ} \mathrm{C}$ & 24 & $220 \mathrm{~nm}$ \\
\hline Ravi Kumar et al. & Gradient & $\begin{array}{l}\text { Inertsil ODS-3 V, } 150 \\
\mathrm{~mm} \times 4.6 \mathrm{~mm}, 5 \mu \mathrm{m}\end{array}$ & $\begin{array}{l}\text { Mobile phase A: Ammonium } \\
\text { formate buffer, }(\mathrm{pH} 4.7) \text { mobile } \\
\text { phase B: Acetonitrile }\end{array}$ & $35^{\circ} \mathrm{C}$ & 10.17 & $220 \mathrm{~nm}$ \\
\hline
\end{tabular}

RP-HPLC: Reverse-phase-high-performance liquid chromatography 
Table 3: Optimized chromatographic conditions of DE parameters

\begin{tabular}{ll}
\hline Parameter & Solvents \\
\hline Mobile phase & $\begin{array}{l}\text { Acetonitrile:phosphate } \\
\text { buffer }(\mathrm{pH} 2.5)(33: 67 \mathrm{v} / \mathrm{v})\end{array}$ \\
Column & C18 \\
Diluents & Mobile phase (acetonitrile:phosphate \\
& buffer $(\mathrm{pH} 2.5)(33: 67 \mathrm{v} / \mathrm{v})$ \\
Column temperature & $50^{\circ} \mathrm{C}$ \\
Wavelength & $225 \mathrm{~nm}$ \\
Injection volume & $10 \mu \mathrm{L}$ \\
Flow rate & $1.0 \mathrm{ml} / \mathrm{min}$ \\
Runtime & 70 \\
Retention time & 25.895 \\
\hline V/V: Volume/volume &
\end{tabular}

Table 4: System suitability results

\begin{tabular}{|c|c|c|c|c|}
\hline S. No & RT & Area & Tailing factor & TP \\
\hline 1 & 26.662 & 265006 & 1.063 & 13174 \\
\hline 2 & 26.632 & 261320 & 1.052 & 13891 \\
\hline 3 & 26.554 & 265518 & 1.077 & 13453 \\
\hline 4 & 26.576 & 263571 & 1.063 & 13718 \\
\hline 5 & 26.52 & 264489 & 1.077 & 13626 \\
\hline Mean \pm SD & $26.5888 \pm 0.05773$ & $263981 \pm 1652.28$ & & \\
\hline$\%$ RSD & 0.21714 & 0.62591 & & \\
\hline Limit & NMT $2 \%$ & NMT 5\% & & \\
\hline
\end{tabular}

SD: Standard deviation, \%RSD: Percent relative standard deviation

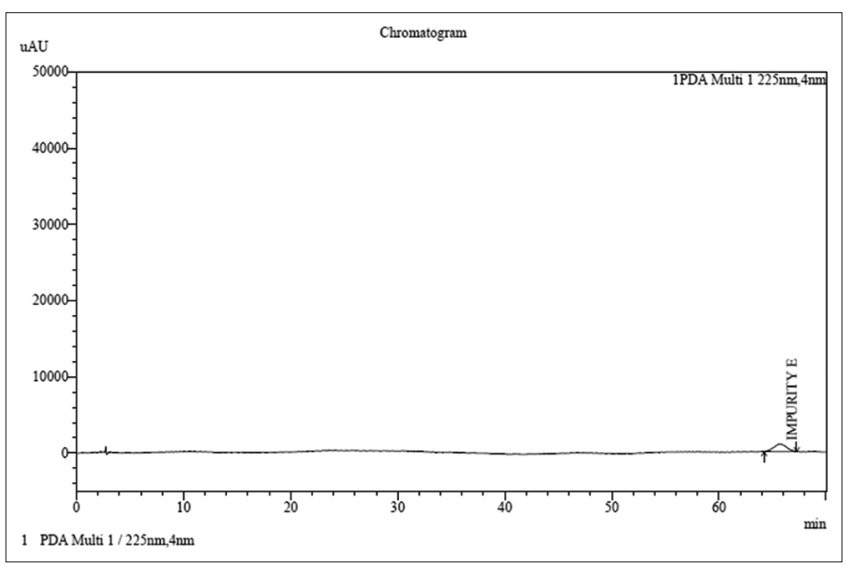

Fig. 10: Chromatogram of Impurity E

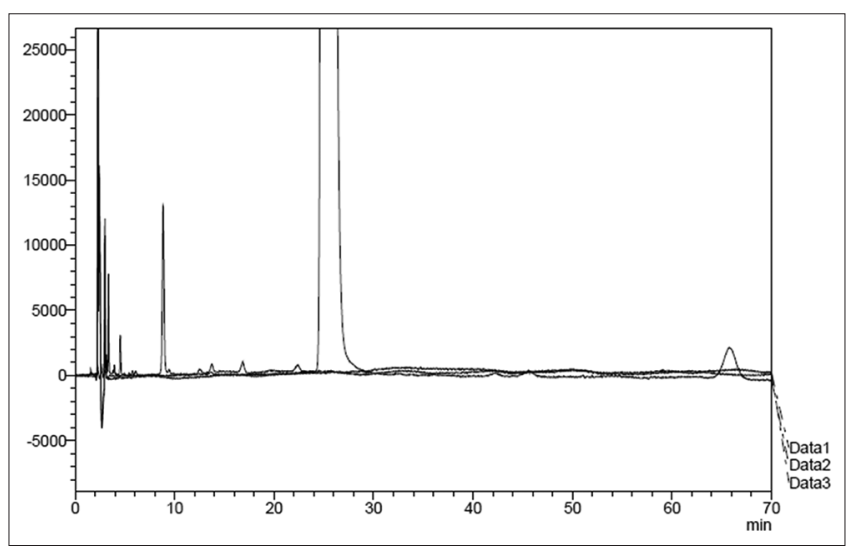

Fig. 11: Overlay chromatograms of blank, placebo, and Dabigatran Etexilate sample

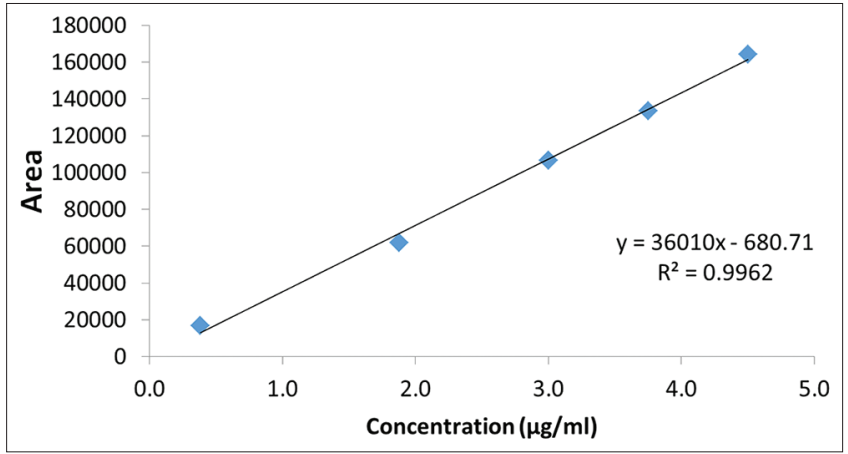

Fig. 12: Linearity graph of unknown impurity (Dabigatran Etexilate)

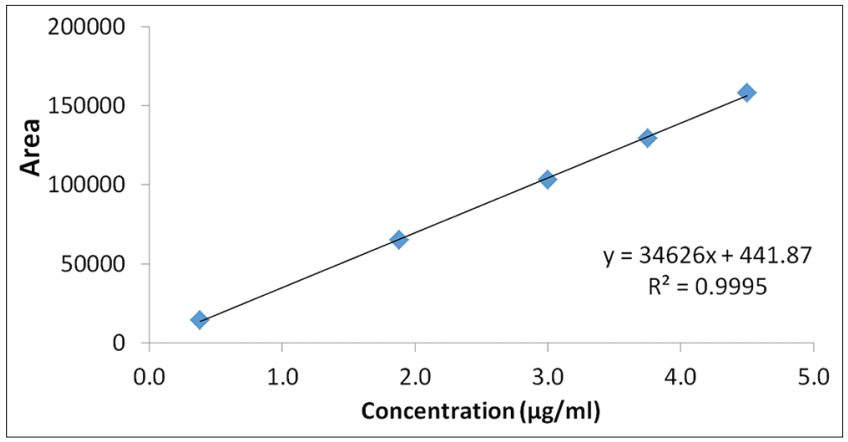

Fig. 13: Linearity graph of Impurity Area

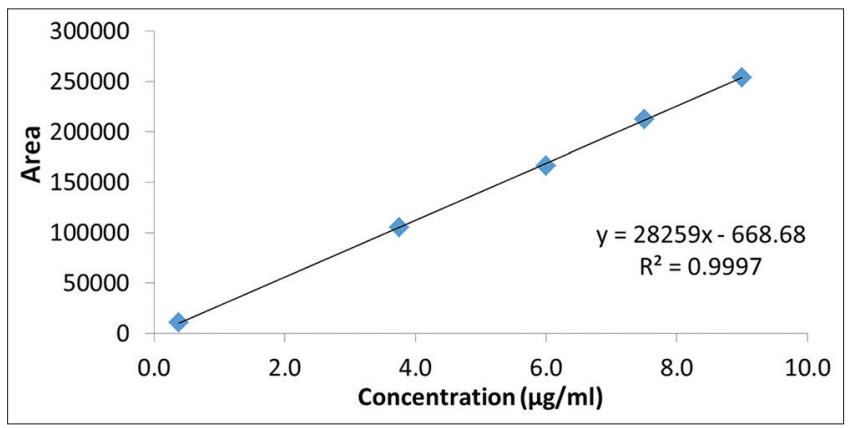

Fig. 14: Linearity graph of Impurity B

phosphoric acid (AR grade). HPLC grade acetonitrile was used for mobile phase preparation.

\section{Instrumental and analytical conditions}

Chromatographic analysis was performed on Princeton SPHER-100 C18 $(250 \times 4.6 \mathrm{~mm}, 5 \mu \mathrm{m}) \mathrm{HPLC}$ column, maintained at $50^{\circ} \mathrm{C}$ column temperatures, $6^{\circ} \mathrm{C}$ sample tray temperature, and detection monitored at $225 \mathrm{~nm}$. The mobile phase used in this analysis consists of an Acetonitrile:phosphate buffer ( $\mathrm{pH} 2.5)$ (33:67 V/V). The mobile phase was filtered, degassed before use. The flow rate was maintained at $1.0 \mathrm{ml} / \mathrm{min}$. The injector volume of standard and sample was $10 \mu \mathrm{L}$. The solution was injected, and chromatograms were recorded [14]. The optimized chromatographic conditions of DE are in Table 3 .

\section{Preparation of mobile phase}

Preparation of $0.05 \mathrm{M}$ potassium dihydrogen phosphate buffer pH 2.5 for mobile phase

Weigh and transfer $6.8 \mathrm{~g}$ of potassium dihydrogen phosphate in $1000 \mathrm{ml}$ of volumetric flask, add $800 \mathrm{ml}$ of water and sonicate to dissolve for 15 
Table 5: Precision results of Impurity A, B, and E and unknown

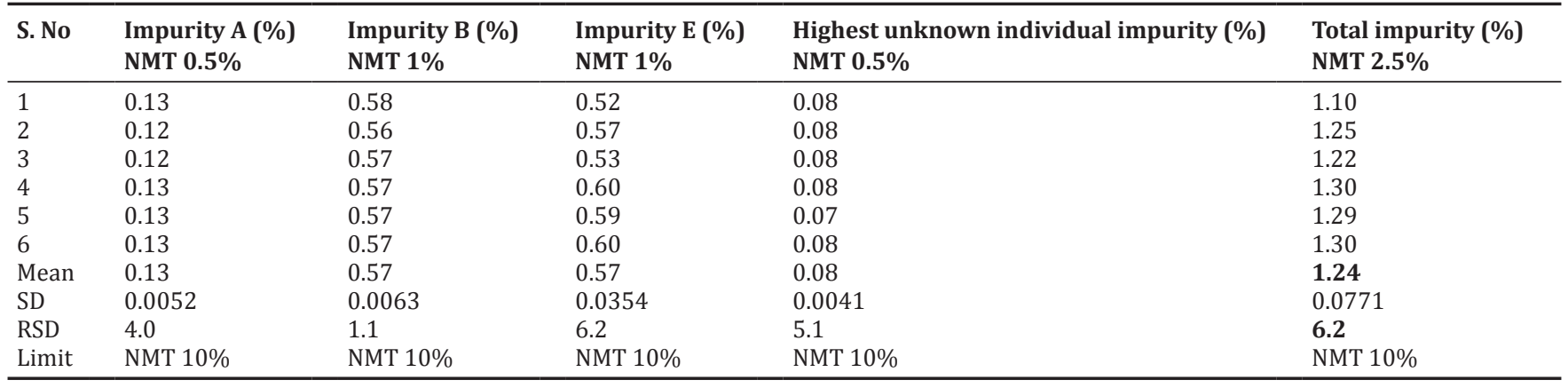

SD: Standard deviation, \%RSD: Percent relative standard deviation

Table 6: Linearity of unknown Impurity (DE)

\begin{tabular}{lll}
\hline Sample name & Concentration $(\boldsymbol{\mu g} / \mathbf{m l})$ & Mean area \\
\hline LOQ & 0.38 & 16754 \\
$50 \%$ & 1.88 & 61773 \\
$80 \%$ & 3.00 & 106535 \\
$100 \%$ & 3.75 & 133697 \\
$120 \%$ & 4.50 & 164328 \\
Correlation coefficient & 0.9962 & \\
$\left(\mathrm{r}^{2}\right)$ & & \\
\hline DE: Dabigatran Etexilate, LOQ: Limit of quantitation
\end{tabular}

Table 7: Linearity of Impurity A

\begin{tabular}{lll}
\hline Sample name & Concentration $(\boldsymbol{\mu g} / \mathbf{m l})$ & Mean area \\
\hline LOQ & 0.38 & 14488 \\
$50 \%$ & 1.88 & 65094 \\
$80 \%$ & 3.00 & 103065 \\
$100 \%$ & 3.75 & 129482 \\
$120 \%$ & 4.50 & 157884 \\
Correlation coefficient & 0.9995 & \\
$\left(\mathrm{r}^{2}\right)$ & & \\
\hline LOQ: Limit of quantitation & &
\end{tabular}

Table 8: Linearity of Impurity B

\begin{tabular}{lll}
\hline Sample name & Concentration $(\boldsymbol{\mu g} / \mathbf{m l})$ & Mean area \\
\hline LOQ & 0.38 & 10811 \\
$50 \%$ & 3.75 & 105075 \\
$80 \%$ & 6.00 & 166320 \\
$100 \%$ & 7.50 & 212931 \\
$120 \%$ & 9.00 & 254049 \\
Correlation coefficient & 0.9997 & \\
$\left(\mathrm{r}^{2}\right)$ & & \\
\hline LOQ: Limit of quantitation & &
\end{tabular}

Table 9: Linearity of Impurity E

\begin{tabular}{lll}
\hline Sample name & Concentration $(\boldsymbol{\mu g} / \mathbf{m l})$ & Mean area \\
\hline LOQ & 0.38 & 9433 \\
$50 \%$ & 3.75 & 88396 \\
$80 \%$ & 6.00 & 148065 \\
$100 \%$ & 7.50 & 182737 \\
$120 \%$ & 9.00 & 214620 \\
Correlation coefficient & 0.9991 & \\
$\left(\mathrm{r}^{2}\right)$ & & \\
\hline
\end{tabular}

LOQ: Limit of quantitation

min, and dilute to volume with water. Adjust $\mathrm{pH} 2.5 \pm 0.05$ using dilute (10\%) phosphoric acid. Filter the solution using a $0.45 \mu$ filter.

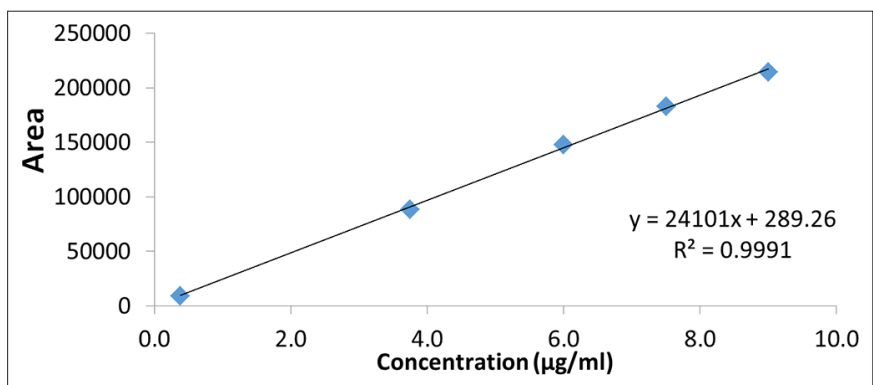

Fig. 15: Linearity graph of Impurity E

\section{Mobile phase}

Prepare a filtered and degassed mixture of acetonitrile and buffer $\mathrm{pH}$ 2.5 in the ratio of $(33: 67 \mathrm{v} / \mathrm{v})$.

Preparation of standard solution

Weigh accurately and transfer DEM working standard (about $87 \mathrm{mg}$ ) about eq. to $75 \mathrm{mg}$ of DE in $50 \mathrm{ml}$ of volumetric flask, add $25 \mathrm{ml}$ of methanol, sonicate to dissolve for $15 \mathrm{~min}$, and dilute to volume with methanol. Pipette out $5.0 \mathrm{ml}$ of the resulting solution in $50 \mathrm{ml}$ of volumetric flask and dilute to volume with mobile phase. Further, pipette out $5.0 \mathrm{ml}$ of the resulting solution in $100 \mathrm{ml}$ of volumetric flask and dilute to volume with mobile phase $(7.5 \mu \mathrm{g} / \mathrm{ml})$.

\section{Preparation of sample solution}

Weigh and remove the content of 20 capsules, weigh accurately and transfer pellets eq. to $300 \mathrm{mg}$ of DE in $200 \mathrm{ml}$ of volumetric flask, add $50 \mathrm{ml}$ of water, sonicate to dissolve for $10 \mathrm{~min}$, stir the sample solution for $30 \mathrm{~min}$ by magnetic stirrer, and add about $100 \mathrm{ml}$ of methanol, further stir the sample solution for $10 \mathrm{~min}$ by magnetic stirrer, and dilute to volume with methanol. Centrifuge the resultant solution at $2000 \mathrm{rpm}$ for $3 \mathrm{~min}$ (if required). Pipette out $5.0 \mathrm{ml}$ of the resulting solution in $10 \mathrm{ml}$ of a volumetric flask and dilute to volume with mobile phase, filter through a $0.45 \mu$ pore size nylon membrane filter $(750 \mu \mathrm{g} / \mathrm{ml})$.

\section{RESULTS AND DISCUSSION}

\section{Method validation}

This method was validated according to ICH guidelines to establish the performance characteristics of a method to meet the requirements for the intended application of the method. They were tested using the optimized chromatographic conditions and instruments.

\section{System suitability}

System performance parameters of HPLC method were determined by injecting 5 replicate injections of standard solutions. Parameters such as retention time, area, tailing factor, and number of theoretical plates (N) were determined. From system suitability studies, it is observed that percentage relative standard deviation (RSD) values for retention 
Table 10: Accuracy results for unknown Impurity (DE)

\begin{tabular}{lllll}
\hline Recovery level & Area & Spiked conc. $(\mu \mathrm{g} / \mathbf{m l})$ & Recovered conc. $(\boldsymbol{\mu g} / \mathbf{m l})$ & Recovered $(\%)$ \\
\hline LOQ - 1 & 14622 & 0.38 & 0.410 & 107.9 \\
LOQ - 2 & 13787 & 0.38 & 0.390 & 102.6 \\
LOQ - 3 & 15107 & 0.38 & 0.420 & 110.5 \\
$50 \%-1$ & 66543 & 1.91 & 1.86 & 97.4 \\
$50 \%-2$ & 64616 & 1.91 & 1.80 & 94.2 \\
$50 \%-3$ & 64037 & 1.91 & 1.79 & 93.7 \\
$100 \%-1$ & 137002 & 3.82 & 3.83 & 100.3 \\
$100 \%-2$ & 142491 & 3.82 & 3.98 & 104.2 \\
$100 \%-3$ & 140394 & 3.82 & 3.92 & 102.6 \\
$120 \%-1$ & 177485 & 4.59 & 4.96 & 108.1 \\
$120 \%-2$ & 181911 & 4.59 & 5.08 & 110.7 \\
$120 \%-3$ & 167722 & 4.59 & 4.68 & 102.0 \\
\hline
\end{tabular}

DE: DE: Dabigatran Etexilate, LOQ: Limit of quantitation

Table 11: Accuracy results for Impurity A

\begin{tabular}{lllll}
\hline Recovery level & Area & Spiked conc. $(\boldsymbol{\mu g} / \mathbf{m l})$ & Recovered conc. $(\boldsymbol{\mu g} / \mathbf{m l})$ & Recovered $(\%)$ \\
\hline LOQ - 1 & 12524 & 0.35 & 0.350 & 100.0 \\
LOQ - 2 & 12466 & 0.35 & 0.350 & 100.0 \\
LOQ - 3 & 11761 & 0.35 & 0.330 & 94.3 \\
$50 \%-1$ & 63777 & 1.75 & 1.79 & 102.3 \\
$50 \%-2$ & 63636 & 1.75 & 1.78 & 101.7 \\
$50 \%-3$ & 63931 & 1.75 & 1.79 & 102.3 \\
$100 \%-1$ & 129651 & 3.51 & 3.63 & 103.4 \\
$100 \%-2$ & 129646 & 3.51 & 3.63 & 103.4 \\
$100 \%-3$ & 129457 & 3.51 & 4.62 & 103.1 \\
$120 \%-1$ & 158246 & 4.21 & 4.70 & 105.2 \\
$120 \%-2$ & 168050 & 4.21 & 4.38 & 111.6 \\
$120 \%-3$ & 156337 & 4.21 & & 104.0 \\
\hline
\end{tabular}

LOQ: Limit of quantitation

Table 12: Accuracy results for Impurity B

\begin{tabular}{lllll}
\hline Recovery level & Area & Spiked conc. $(\boldsymbol{\mu g} / \mathbf{m l})$ & Recovered conc. $(\boldsymbol{\mu g} / \mathbf{m l})$ & Recovered $(\%)$ \\
\hline LOQ - 1 & 11110 & 0.34 & 0.310 & 91.2 \\
LOQ - 2 & 10870 & 0.34 & 0.300 & 88.2 \\
LOQ - 3 & 11741 & 0.34 & 0.330 & 97.1 \\
$50 \%-1$ & 106776 & 3.37 & 2.99 & 88.7 \\
$50 \%-2$ & 107522 & 3.37 & 3.01 & 89.3 \\
$50 \%-3$ & 107865 & 3.37 & 3.02 & 89.6 \\
$100 \%-1$ & 216495 & 6.75 & 6.06 & 89.8 \\
$100 \%-2$ & 220683 & 6.75 & 6.18 & 91.6 \\
$100 \%-3$ & 218654 & 6.75 & 6.12 & 90.7 \\
$120 \%-1$ & 257831 & 8.10 & 7.22 & 89.1 \\
$120 \%-2$ & 272410 & 8.10 & 7.62 & 94.1 \\
$120 \%-3$ & 260497 & 8.10 & 7.29 & 91.1 \\
\end{tabular}

LOQ: Limit of quantitation

time and area are found within the limit, i.e., not more than $2 \%$ and not more than $5 \%$, respectively, which indicates good performance of the system. System suitability results are tabulated in Table 4.

\section{Specificity}

It is the ability to asses explicitly the analyte in the presence of components that may be expected to be present. The blank, placebo, standard, sample, Impurity A, Impurity B, and Impurity E solution were prepared and injected in HPLC system for evaluation of specificity of the analytical method.

\section{Observation}

The blank and placebo did not show any interference on the retention time of DE, Impurity A, Impurity B, and Impurity E in sample chromatograms. Hence, it is concluded that analytical method is specific for DE, Impurity A, Impurity B, and Impurity E. Typical chromatogram of blank, standard, placebo, sample, Impurity A, Impurity B, Impurity
E, and overlay chromatogram is shown in Figs. 4-11, respectively. It revealed that the present analytical RP-HPLC method is specific for DE, Impurity A, Impurity B, and Impurity E.

\section{Precision}

The precision of the method expresses the closeness of agreement between a series of measurements obtained from multiple sampling of the same homogeneous sample under prescribed conditions. Precision studies were conducted by preparing six different preparations of the sample solution, and results are reported in term of RSD. The percentage RSD of six preparations for known and unknown impurity in the sample solution was found below $10 \%$; hence, method is precise. The results are tabulated in Table 5 .

Based on the above results, it revealed that the present analytical RP-HPLC method is precise for DE (unknown impurity), Impurity A, Impurity B, and Impurity $\mathrm{E}$. 
Table 13: Accuracy results for Impurity E

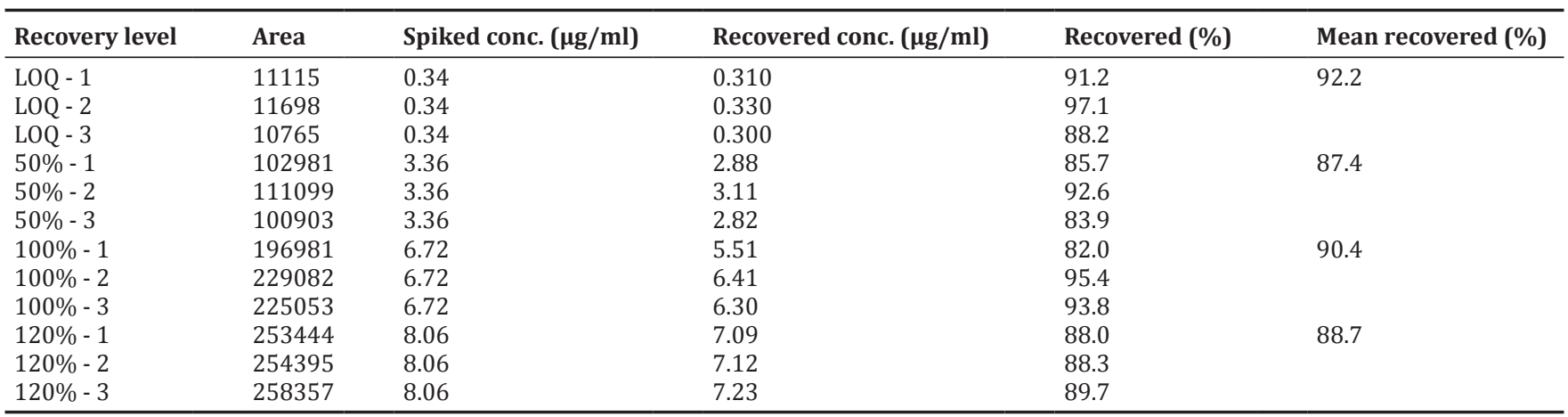

LOQ: Limit of quantitation

Table 14: DE standard solution stability results

\begin{tabular}{lllll}
\hline S. No & Details of SPL & Time (h) & DE area & RSD \\
\hline 1 & STD SS 01 & 0 & 6 & 311733 \\
2 & STD SS 02 & 12 & 312612 & 0.07 \\
3 & STD SS 03 & 18 & 314081 & 0.69 \\
4 & STD SS 04 & 24 & 313756 & 0.99 \\
5 & STD SS 05 & 0.97 & 3177 \\
\hline
\end{tabular}

DE: Dabigatran Etexilate, RSD: Relative standard deviation

Table 15: DE sample solution stability results

\begin{tabular}{lllllll}
\hline S. No & Details of SPL & Time (h) & Impurity A & Impurity B & Impurity E & Total impurity \\
\hline 1 & DE SPL 01 & 0 & 0.03 & 0.24 & 0.28 \\
2 & DE SPL 02 & 6 & 0.04 & 0.24 & 0.29 \\
3 & DE SPL 03 & 12 & 0.04 & 0.25 & 0.33 \\
4 & DE SPL 04 & 18 & 0.05 & 0.24 & 0.35 \\
5 & DE SPL 05 & 24 & 0.06 & 0.25 & 0.4 \\
\hline
\end{tabular}

DE: Dabigatran Etexilate

\section{Linearity}

A series of solutions was prepared using DE (unknown impurity), Impurity A, Impurity $\mathrm{B}$, and Impurity $\mathrm{E}$ standard from limit of quantitation (LOQ) to $120 \%$ of its impurity limits concentration (i.e., DE $0.5 \%$, Impurity A $0.5 \%$, Impurity B $1 \%$, and Impurity E $1 \%$ ). The calibration curve for DE (unknown impurity), Impurity A was linear from 0.38 to $4.5 \mu \mathrm{g} / \mathrm{ml}$ ( $\mathrm{r} 2$ for $\mathrm{DE}=0.996$ and 0.999 , respectively). The calibration curve for Impurity B and Impurity E was also linear from 0.38 to $9.00 \mu \mathrm{g} / \mathrm{ml}$ (r2 for $\mathrm{DE}=0.999$ and 0.999 , respectively). Linearity results of DE (unknown impurity), Impurity A, Impurity B, and Impurity $\mathrm{E}$ are tabulated in Tables 6-9, respectively. Linearity graph of unknown Impurity, Impurity A, Impurity B, and Impurity E is represented in Figs. $12-15$, respectively.

\section{Accuracy}

Accuracy solution was prepared in triplicate from LOQ to $120 \%$ by spiking DE (unknown Impurity), Impurity A, Impurity B, and Impurity $\mathrm{E}$ of its impurity limits concentration (i.e., DE $0.5 \%$, Impurity A $0.5 \%$, Impurity B $1 \%$, and Impurity E $1 \%$ ). Accuracy is calculated by impurity added verses impurities recover. Recovery for DE (unknown Impurity), Impurity A, Impurity B, and Impurity E is found within $80 \%$ to $120 \%$; hence, method is accurate. Accuracy data of unknown Impurity, Impurity A, Impurity B, and Impurity E are presented in Tables 10-13, respectively.

\section{Solution stability for standard and sample solution}

Standard and sample solution was prepared as per method and injected at a different interval such as initial, $6 \mathrm{~h}, 12 \mathrm{~h}, 18 \mathrm{~h}$, and $24 \mathrm{~h}$. The percentage RSD for standard solution is found below 5\%, and percentage impurity change in the sample solution is found below $0.1 \%$ up to $18 \mathrm{~h}$; hence, standard solution is stable up to $24 \mathrm{~h}$, and sample solution is stable up to $18 \mathrm{~h}$. Standard preparation and sample preparation solution stability results are presented in Tables 14 and 15, respectively.

\section{CONCLUSION}

In the present study, the developed method is new, simple, adequate, specific, precise, linear, and accurate for the determination of DE and its impurities in pharmaceutical dosage forms.

\section{ACKNOWLEDGMENT}

The authors wish to thank ZIM Laboratories Limited, Nagpur, India, for providing the DEM drug, impurities, and facilities to perform research work.

\section{AUTHOR'S CONTRIBUTION}

Mr. Shankar Pol, Dr. Rajesh Nawale, and Dr. Vishal Rajkondawar conceived of the presented idea. Mr. Shankar Pol performed analytical method development. Dr. Rajesh Nawale and Dr. Prashant Puranik verified the analytical methods. Dr. Anwar Daud encouraged for research. All authors discussed the results and contributed to the final manuscript.

\section{CONFLICTS OF INTEREST}

The authors declare that they have no conflicts of interest.

\section{REFERENCES}

1. Hauel N, Ries U, Priepke H, Wienen W, Stassen JM, Inventor; Boehringer Ingelheim Pharma AG, Assignee. Disubstituted Bicyclic 
Heterocycles, their Preparation and their use as Medicaments. WIPO Patent Cooperation Treaty (PCT) Patent Application WO1998037075. 1998. p. 1-201.

2. Stangier J, Rathgen K, Stähle H, Gansser D, Roth W. The pharmacokinetics, pharmacodynamics and tolerability of dabigatran etexilate, a new oral direct thrombin inhibitor, in healthy male subjects. Br J Clin Pharmacol 2007;64:292-303.

3. Boehringer Ingelheim. USFDA PRADAXA (Dabigatran Etexilate Mesylate) Capsules for Oral use Label/Patient Information Leaflets. US@FDA; 2010.p. 1-9.

4. Drugbank.ca/drugs/DB06695. Dabigatran Etexilate Mesylate-Drug Bank; c2018. Available from: http://www.drugbank.ca/drugs/DB06695. [Last cited on 2018 Apr 22]

5. PRADAXA (Dabigatran Etexilate Mesylate) Capsules $75 \mathrm{mg}$ and 150mg, NDA 22-512, Center for Drug Evaluation and Research; 2010. p. 1-71.

6. Kumar VD, Balaraju K, Kumar AA. A Rapid RP-HPLC method development and validation for the quantitative estimation of dabigatran etexilate mesylate in capsules. Int J Pharm Pharm Sci 2015;7:352-6.

7. Hussain SS, Bhavani G, Kumar AA. UV spectrophotometric assay method development and validation of dabigatran etexilate in capsules. Int J Pharm Pharm Sci 2015; 7:286-9.

8. Bomma S, Haque MA, Reddy PR, Bakshi V. Method development and validation for the determination of related compounds in dabigatran etexilate mesylate by RP-HPLC. Int J Med Nanotechnol 2014;1:186-93.

9. Dare M, Jain R, Pandey A. Method validation for stability indicating method of related substance in active pharmaceutical ingredients dabigatran etexilate mesylate by reverse phase chromatography. J Chromatogr Sep Tech 2015;6:1-10.

10. Nagadeep J, Kamaraj P, Arthanareeswari M. Gradient RP-HPLC method for the determination of potential impurities in dabigatran etexilate in bulk drug and capsule formulations. Arabian J Chem 2015. (Press).

11. Sreenivas N, Raghu BK, Douglas SP, Ray UK. Validation of stabilityindicating reverse phase HPLC method for the determination of related substances in dabigatran etexilate mesylate drug substance. Pharm Lett 2015; 7:272-9.

12. Hanimi RB, Maram RK, Woo HC, Venkat BR, Pasagadugula V. QbD approach method development for estimation of dabigatran etexilate along with its impurities and identification of degradants in capsule dosage form. Am J Anal Chem 2016;7:494-524

13. Lee CR, Guivarch F, Van Dau CN, Tessiera D, Krstulovic AM. Determination of polar alkylating agents as thiocyanate/isothiocyanate derivatives by reaction headspace gas chromatography. Analyst 2003; $128: 857-63$.

14. Kulkarni AA, Vaidya IS. Flow injection analysis: An overview. J Crit Rev 2015;2:19-24. 